\title{
Sentido e significado: o prazer do risco nos velejadores
}

\section{Sense and meaning: the pleasure of the risk in sailors}

Priscilla Pinto Costa da Silva ${ }^{1}$

Emília Amélia Pinto Costa da Silva ${ }^{2}$

Andrea Maria Pires Azevedo ${ }^{3}$

Petrucio Venceslau de Moura ${ }^{4}$

Gisele Maria Schwartz ${ }^{2}$

Simone Rechia ${ }^{2}$

Clara Maria Silvestre Monteiro de Freitas ${ }^{1}$

\section{Resumo}

O estudo objetiva analisar os sentidos e significados do prazer do risco de velejadores. Trata-se de uma pesquisa de campo, participando 19 velejadores do Iate Clube da Paraíba, na cidade de João Pessoa - Paraíba. Foi utilizado um questionário e um roteiro de entrevista semiestruturada. Para análise dos dados utilizou-se o software AQUAD, que auxiliou na obtenção da frequência absoluta das palavras, para definir as categorias analíticas, interpretadas por meio da análise de conteúdo. Os resultados conduziram a três categorias analíticas: sentidos e significados da prática da vela; os riscos na prática da vela; e o prazer da prática da vela. As categorias revelaram que os sentidos e significados desta prática contribui para a educação e respeito pela natureza, despertando novas emoções e sensações, relacionadas à atividade física e ao lazer. Os entrevistados apontaram que os riscos são inerentes a prática da vela e se associam à negligência, falta de manutenção e mudanças climáticas, sendo necessário, para segurança, crenças, equipamentos básicos e tecnológicos.

\section{Palavras-chave}

Prazer. Risco. Atividades de Lazer.

\begin{abstract}
The study aims to analyze the senses and meanings of sailors' risk pleasure. This is a field research with 19 sailors from Iate Clube da Paraiba, in the city of João Pessoa-Paraiba. We used a questionnaire and a semi-structured script for interviews. The data analysis used the software AQUAD, which generated the absolute frequency of words used to define the analytical categories, interpreted through content analysis. The results led to three analytical categories: senses and meanings of sailing; risks in sailing, and pleasure of sailing. The categories revealed that the senses and meanings of this practice contribute to the education and respect for nature, awakening new emotions and sensations related to physical activity and leisure. The interviewees indicated that the risks are inherent to sailing and are associated with negligence, lack of maintenance and climate change, being necessary for safety issues, beliefs, basic and technological equipments.
\end{abstract}

\section{Keywords}

Pleasure; Risk; Leisure Activities.
Rev Bras Ativ Fis Saúde p. 75-85 DOI: http://dx.doi.org/10.12820/23171634.2013v18n1p75

1 Programa de Pós-graduação em Educação Física UPE/UFPB, Recife, PE, Brasil.

2 Universidade Federal do Paraná, Curitiba $P R$, Brasil.

3 Universidade de Brasilia, Brasilia, DF, Brasil.

4 Instituto Federal de Pernambuco, Recife, $P E$, Brasil. 


\section{INTRODUÇÃO}

A prática da vela está inserida no universo das práticas corporais na natureza, sendo estas desenvolvidas em um ambiente incerto e desconhecido, dependente das ações da natureza, como a força do vento e a água, as quais quando intercedem no barco mediado pelo ser humano, resultam na realização da atividade. As práticas corporais na natureza estão sujeitas aos riscos que abrangem estes espaços, tais como, variação climática, aparecimento de animais que podem gerar doenças, além do risco de acidente e lesão que algumas práticas podem proporcionar ${ }^{1}$.

As emoções que envolvem as práticas corporais na natureza estão imersas em atividades que o sujeito controla seu próprio risco. Le Breton ${ }^{2}$ aponta em seus estudos, que essa mistura da emoção com o risco, o qual está sendo controlado, gera diferentes conceitos, em que o sujeito se une ao mundo intensificando o seu ser. Sob outro prisma, o estudo de Suassuna et al. ${ }^{3}$ apresenta que há uma crescente racionalização de controle da natureza, o que conduz aos pensamentos de Morin ${ }^{4}$ e Bento ${ }^{5}$ quando apontam para a separação do ser humano e a natureza, do corpo e do espírito, ameaçando a qualidade da relação ser humano-natureza, bem como, da natureza com a cultura. Neste mesmo sentido, retoma-se Suassuna et al. ${ }^{3}$ quando informam sobre o controle da natureza, o que gera, na verdade, o seu descontrole, impossibilitando ao ser humano a compreensão de si mesmo como elemento da natureza. Seguindo este pensar, $\operatorname{Costa}^{6}$ aponta que o fenômeno do desporto ajuda ao ser humano revelar sua natureza e o sentido de suas metas.

Nesta perspectiva, é importante trazer os estudos à luz da complexidade do sentido e do significado da relação ser humano-natureza, sendo necessário, no entanto, compreender suas diferenças. Seguindo as ideias dos estudos de Vygotsky, Bakhtin e Abbagnano ${ }^{7,8,9}$, a caracterização do termo sentido diz respeito ao sistema complexo, que desenvolve uma interligação entre o tempo e o espaço, possibilitando, a partir de significações precisas, compreender a capacidade de receber sensações emanadas das próprias ações. Por outro lado, o significado é caracterizado pela manifestação, tornando-se produto da construção social, em que o passado e o presente se encontram interligados.

Pesquisadores como Le Breton, Spink, Pereira, Carvalho e Marinho 2,10,11,12,13,14,15 dedicaram seus estudos aos fatores interligados ao risco nas práticas corporais na natureza. Nesta concepção, incide uma nova forma de valorização do corpo e dos elementos hedonistas, além de intensificar o sentido da vida em busca do prazer do risco. Seguindo os autores citados, o sentido e o significado das práticas corporais na natureza estão interligados ao risco, visto como elemento sedutor para o alcance das sensações de prazer que tais práticas proporcionam. Entretanto, nestes estudos não foram evidenciadas as práticas que agregam outro elemento importante, capaz de inferir novas variáveis ao processo de compreensão das subjetividades envolvidas nesta relação humana com a natureza, que diz respeito ao elemento água. Este elemento traz novas inquietações, evocando imaginários ainda mais complexos, que instigaram o desenvolvimento desta reflexão. Assim, questionase quais as relações dos sentidos e significados do prazer do risco vivenciados na prática da vela? Diante deste cenário, o objetivo do estudo foi analisar os sentidos e significados do prazer do risco de velejadores.

\section{MÉTODOS}

Trata-se de uma pesquisa de campo de caráter qualitativo, por permitir a compre- 
ensão do conhecimento de uma realidade social por meio das informações relativas a um problema, na descoberta de novos fenômenos e nas relações de um determinado fato, aproximando o pesquisador às experiências com o cenário pesquisado ${ }^{16}$.

Os atores sociais selecionados foram 19 velejadores do Iate Clube da Paraíba, da cidade de João Pessoa - Paraíba - Brasil, com idades entre 19 e 64 anos, sendo apenas um dos velejadores do sexo feminino. $\mathrm{O}$ critério de inclusão adotado foi o tempo de experiência da prática da vela, tendo sido selecionados aqueles com, no mínimo, 5 anos de prática, de forma arbitrária.

Como instrumento para a coleta de dados, utilizou-se um questionário para caracterização sociodemográfica dos atores sociais e um roteiro de entrevista semiestruturada, por obedecer a um critério que envolve questões pertinentes ao tema estudado, permitindo ao pesquisador incluir outras perguntas, quando necessário, para o entendimento de um determinado assunto, tornando eficaz a obtenção de dados desejados ${ }^{17}$. Além disso, foi utilizado um roteiro observacional, para obtenção de informações da realidade dos fatos e fenômenos, por meio dos sentidos e comportamentos, permitindo uma aproximação à realidade do que está sendo observado por parte do pesquisador, o qual passou por um treinamento prévio para aplicação dos intrumentos do estudo ${ }^{18}$.

O trabalho de campo foi realizado aos sábados e domingos, conforme planejamento pré-estabelecido pelo Comodoro do Iate Clube da Paraíba. Inicialmente, foram esclarecidas todas as dúvidas referentes à participação no estudo, posteriormente, com base na anuência dos convidados, foi apresentado e assinado o Termo de Consentimento Livre e Esclarecido, seguido da aplicação do questionário e da entrevista.

As entrevistas foram gravadas, transcritas e, em seguida, submetidas ao soft Analysis of Qualitative Data (AQUAD) 6, que auxiliou na obtenção da frequência absoluta das palavras. Em seguida foram formadas as categorias analíticas, exploradas a partir da Análise de Conteúdo, por ser uma técnica metodológica que dá suporte às análises das entrevistas, por meio dos procedimentos sistêmicos da descrição dos conteúdos ${ }^{18}$. Para a construção dos diagramas que apresentam as categorias de análise foi utilizado o soft GoDiagram Express versão 2.6.2.

Ressalta-se que foram respeitadas as diretrizes regulamentadas pela Resolução no 196/96 do Conselho Nacional de Saúde/MS, sendo o projeto aprovado pelo Comitê de Ética em Pesquisa com seres humanos da Universidade de Pernambuco, sob o registro 231/09.

\section{RESULTADOS E DISCUSSÃO}

Os resultados e a discussão estão apresentados em três categorias analíticas: sentidos e significados da prática da vela; os riscos na prática da vela; e o prazer da prática da vela. Estas categorias conduzem as práticas corporais na natureza com enfoque nas sensações cheias de sentidos e significados, os quais são encontrados na busca do prazer por meio do risco. Contudo, na prática da vela, a integração do velejador com a natureza consiste, principalmente, nos elementos que incidem na ação de velejar, envolvendo o mar, o vento, as fases da lua, além da concepção do corpo que veleja.

\section{Sentidos e Significados da Prática da Vela}

No que concerne à caracterização dos atores sociais entrevistados, a maioria revelou que o interesse pela prática da vela surgiu por meio de familiares que já pra- 
ticavam, ou por convites de amigos velejadores e, desta forma, ingressaram nesta prática. Muitos iniciaram ainda na infância, o que facilitou maior conhecimento da natureza, segundo Suassuna et al. ${ }^{3}$. A prática da vela permite despertar novas sensações a partir das vivências, contribuindo na busca de novos sentidos e significados, tanto para a prática em si, quanto para a vida do velejador. O diagrama a seguir apresenta a relação dos sentidos e dos significados que a prática da vela tem na vida dos velejadores participantes do estudo.

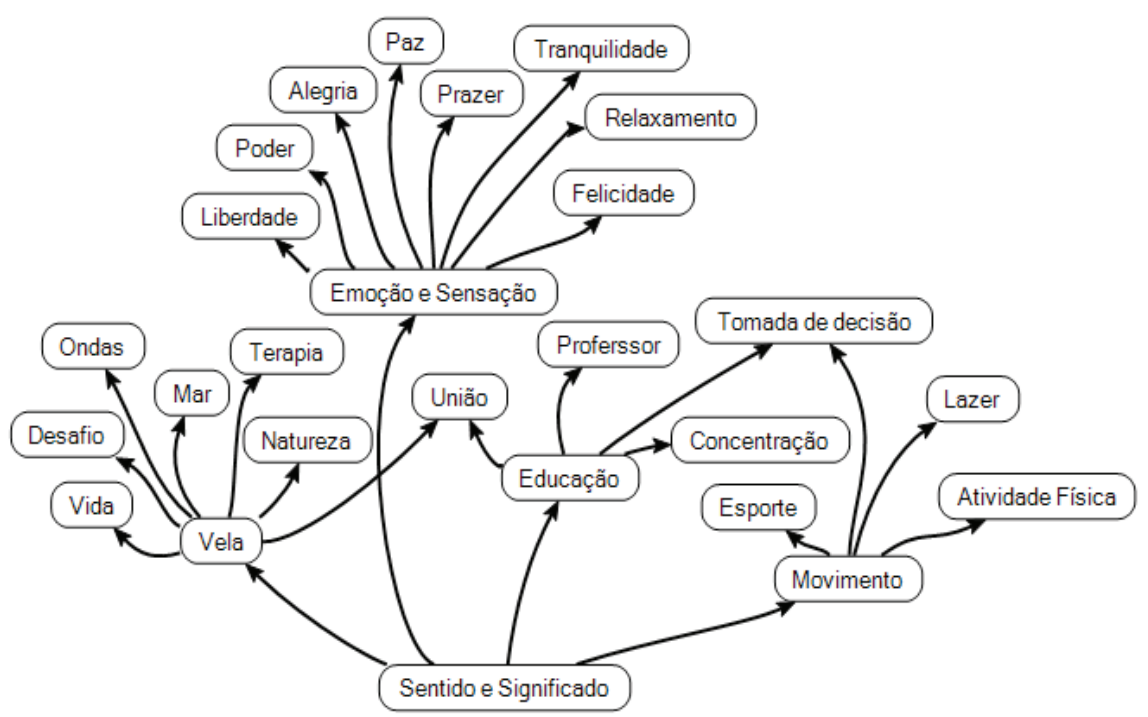

Figura 1 - Sentido e Significado de Velejar.

A categoria sentido e significado, caracteriza-se pelas acepções despertadas a partir da prática da vela, usufruindo as circunstâncias escolhidas pelo sujeito, na condição de ganhar um "troféu" que intensifique o ser, além de trazer a lembrança do momento de coragem tendo êxito e a garantia de uma vida com mais energia ${ }^{2}$. As subcategorias: vela, emoção/sensação, educação e movimento, dizem respeito às interrelações reveladas pelo sentido e significado que a prática da vela constitui na vida dos velejadores participantes do estudo.

A subcategoria vela representa as mudanças que esta prática trouxe para a vida dos velejadores, neste sentido, o entrevistado 12 declara algumas transformações observadas, ao afirmar que "[...] a vela me traz, primeiro o respeito pelo mar, e o respeito pelas pessoas". Outro entrevistado, o de número 4, ressaltou que a vela "[...] é uma terapia ocupacional, é uma maneira de você trabalhar a mente de uma forma bem intensa”. A esse respeito, Marinho ${ }^{15}$ aponta que as práticas corporais na natureza se manifestam de forma ambígua, podendo ser tranquilas, reflexivas, contemplativas e, por outro lado, ágeis e compulsivas.

Nessa mesma linha de pensamento, Lavoura, Schwartz e Machado ${ }^{19}$, revelaram que tais práticas apresentam, também, ambiguidade no que refere aos aspectos emocionais, ora proporcionando sensações prazerosas; ora apresentando sensações receosas, como exemplo, o medo. No entanto, quanto ao sentido e significado que a prática da vela traz para a vida dos velejadores, as sensações são positivas, como revela o entrevistado 12 "[...] é um esporte que traz paz e tranquilidade, pra você ter paciência. É um esporte que agrega um bocado de valores".

Outra categoria encontrada faz referência à educação, que consiste nos valores adquiridos pelas vivências a partir da prática da vela, como a união e a compreensão, relatadas pelo entrevistado 19 , quando aponta que é preciso “[...] compreender 
os outros, saber o problema que os outros têm”. Seguindo este raciocínio, os estudos de Monteiro ${ }^{20}$ apresentam que as práticas corporais na natureza trazem um sentimento de amizade, capaz de facilitar a compreensão dos outros atores sociais participantes. Outra variável analisada trata da tomada de decisão, apresentada pelo entrevistado 7, quando afirma que a prática da vela “[...] dá um poder imenso de tomada de decisão [...] é você e o equipamento. Ali você comanda tudo e isso aí na sua vida pessoal também, lhe dá um poder de decisão extraordinário”. Estas revelações corroboram as encontradas nos estudos de Marinho ${ }^{15}$, a partir das práticas corporais na natureza, em que o corpo passa por transformações, capaz de receber e emitir informações, as quais devem ser concisas e as tomadas de decisões imediatas.

A subcategoria movimentação consiste nas atividades em que os entrevistados consideram a prática da vela, sendo esta tomada como um esporte, atividade física, ou na perspectiva do lazer, como enfatiza o entrevistado 17 "[...] pra mim é muito importante, pois é o meu esporte principal, e também eu uso como forma de lazer". No que concerne ao lazer, os escritos ${ }^{21,20,15,22,23}$ ressaltam que as práticas corporais na natureza como forma de vivência do lazer, manifestam características inovadoras, despertando novas sensações corporais, as quais são diferenciadas dos esportes tradicionais, tendo em vista um cenário desconhecido para o ser humano.

Observa-se que, em algumas subcategorias, as variáveis são coincidentes, como é o caso da expressão união, por apresentar afinidade, tanto quando se evidencia apenas a prática da vela, como para a perspectiva de educação, revelando um sentido multidisciplinar. No tocante à variável tomada de decisão, as subcategorias educação e movimentação, relacionaram-se entre si. Contudo, as subcategorias apresentadas recairam no universo dos sentidos e significados existentes na prática da vela para os velejadores entrevistados.

\section{Os Riscos na Prática da Vela}

Esta categoria apresenta as situações de riscos durante a prática da vela e advém das circunstâncias enfrentadas pelos velejadores, oscilando entre a segurança e vulnerabilidade, por meio das incertezas do $\operatorname{mar}^{24}$. $\mathrm{O}$ autor aponta que o sujeito faz um pacto com a morte, mas não intencional, sendo o corpo uma moeda de troca e a natureza um espaço de conciliação, assim, a morte é mantida à distância, sendo gerenciada pela determinação pessoal e o conhecimento que o velejador tem do mar e do barco. A ida ao mar é um desafio individual, à procura de uma legitimidade e de reconhecimento, tendo o mar como elemento ameaçador a ser superado ${ }^{24}$. Assim, o diagrama a seguir revela as situações de riscos enfrentadas pelos velejadores entrevistados.

A categoria situação de risco se refere aos acidentes e incidentes decorrentes na prática da vela, podendo ser provocados pelas imprudências e pela falta de prevenção relativa aos cuidados básicos, muitas vezes, resultados da exacerbada autoconfiança dos praticantes ${ }^{25,2,3}$. As subcategorias causa, circunstância, sensação e salvamento, revelam as fases das situações de risco evidenciando as causas, circunstâncias, sensações e salvamentos, seguidas das variáveis de maior frequência para cada uma delas.

A subcategoria causa, revela o que provocou a situação de risco no ponto de vista dos velejadores, sendo que os depoimentos apontam ocorrências que recaem na falta de experiência, manutenção, negligência, quebra de equipamento, como revela o entrevistado 11 “[...] na regata Recife-Noronha, nós estávamos voltando de Noronha pra João Pessoa quando a vela mestre se rasgou e o capitão do barco não era tão experiente". Este depoimento lembra os estudos de Le Breton ${ }^{24}$ ao apontar que o marinheiro deve ter o contato permanente com os elementos natu- 


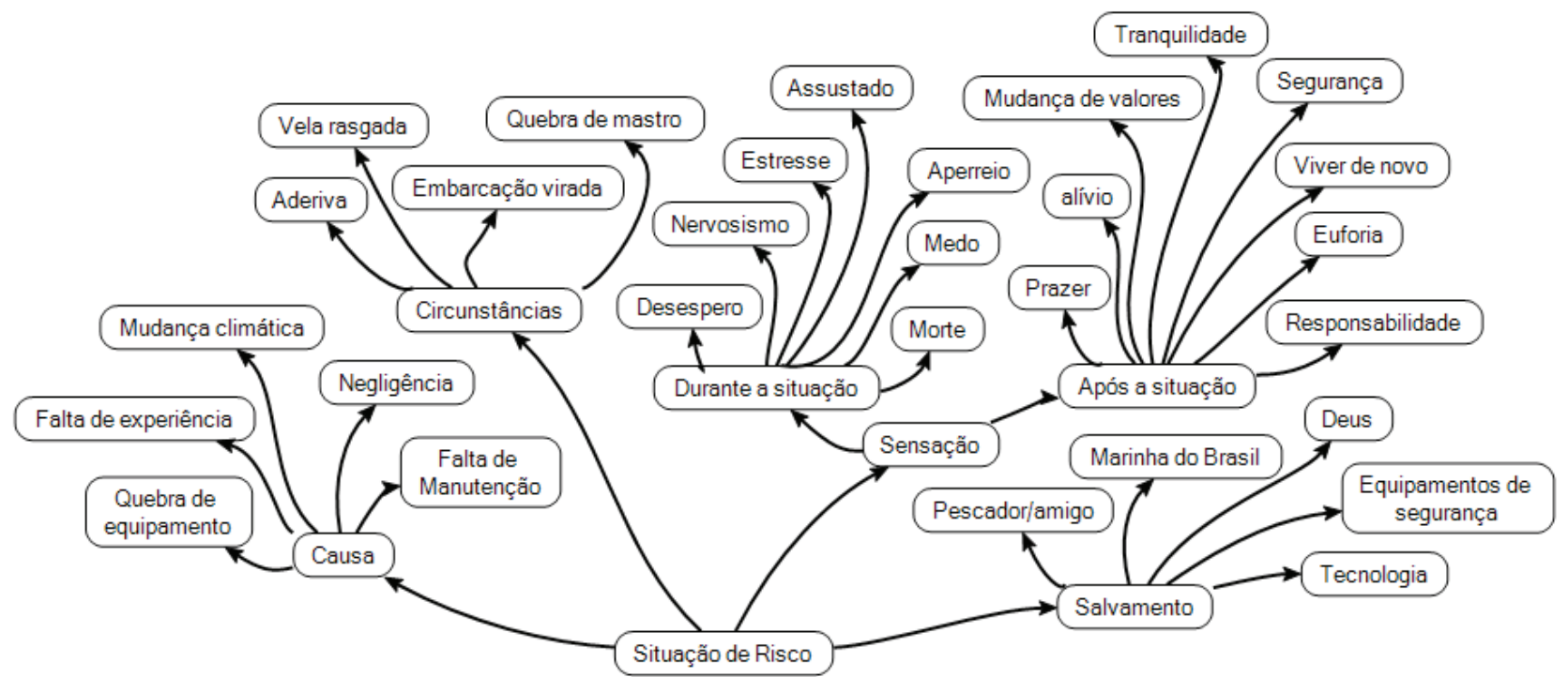

Figura 2 - Fases que compõem a experiência da situação de risco na prática da vela.

rais, e 'sente', por meio do barco e do corpo, sensações, as quais o situam no mundo. Contudo, Le Breton ${ }^{2}$ aponta que tais práticas são consideradas um jogo com a morte, arrisca-se a própria vida em situações de perigos e ameaças, por meio das incertezas vivenciada na natureza.

Outro aspecto que vale ressaltar nesta subcategoria, refere-se às situações de riscos decorrentes das mudanças climáticas, as quais podem provocar situações ameaçadoras à vida dos velejadores, deixando-os em situações desagradáveis. Quanto à categoria circunstâncias, o entrevistado 7 lembra que:

[...] eu fiquei 2 dias e 1 noite a deriva, eu e uma proeira, amiga minha [...] a gente saiu no período de inverno com o clima totalmente favorável, o clima mudou completamente [...] viramos o barco nessa tempestade, e ele nos levou pra o alto mar. [...] na mesma noite do sábado a gente já deixou de ver terra, pra você ter uma ideia da gravidade desse acidente no domingo de 5 horas da tarde um pescador nos encontrou. Agora o meu barco foi encontrado na Costa de Natal, e eu fui encontrado próximo ao Iate Clube aqui.

Neste cenário, Le Breton ${ }^{2}$ salienta que a insegurança do praticante e a sensação de estar sufocado projetam as condutas simbólicas com a morte, em busca pela sobrevivência, o que foi perdido em si mesmo, no entanto, estas situações, como a relatada pelo entrevistado, são valiosas para o sujeito encontrar o seu lugar no mundo. $\mathrm{O}$ autor ainda aponta que as condutas de risco se caracterizam por um sentimento confuso e de sofrimento, para encontrar uma intensidade de ser e compartilhar com as outras pessoas as circunstâncias enfrentadas.

Nessa direção, a subcategoria sensação está dividida em duas fases: a primeira caracteriza as sensações durante a situação de risco, em que os velejadores relataram sensações negativas, como declara o entrevistado 19: “[...] a sensação era que eu ia morrer e que não chegaria a ver meus filhos novamente". Lavoura et al. ${ }^{19}$ encontraram nos estudos sobre os aspectos emocionais nas práticas de aventura, que sensações como o medo não deve ser apreciada apenas como negativa, que causam uma reação de fuga nos sujeitos, assim, tais sensações preservam a condição humana, por sinalizar as ameaças e perigos, tendo que ser consideradas, inclusive, sob este aspecto positivo. 
Esses autores apontaram que o risco quando controlado, como no caso da contribuição dos recursos tecnológicos, os praticantes se lançam na natureza e a sensação de medo é configurada como uma emoção excitante, interligada ao prazer, o que concerne à segunda fase das sensações, após a situação de risco, destacando as percepções positivas, como aponta o entrevistado 7, quando revela suas transformações após a situação de risco, "[...] isso aí é o grande diferencial, você muda os valores na sua vida pessoal e profissional [...] você fica uma pessoa muito mais zen, mais tranquila. Você muda pra melhor”. Na argumentação de Pereira ${ }^{26}$, Marinho $^{22}$, Le Breton ${ }^{2}$ e Bruhns ${ }^{23}$, as práticas corporais na natureza revelam características pessoais, quando os sujeitos passam por situações singulares até então desconhecidas para si, encontrando um enraizamento em sua existência. Tais resuldatos encontram respaldo no estudo de Spink, Galindo, Cañs e Souza ${ }^{27}$ que ressaltam a existencia de uma dimensão positiva nas situações de risco.

No que diz respeito à subcategoria salvamento, a maioria dos velejadores relatou que Deus os salvaram das situações de risco, como manifestou o entrevistado 5 “[...] então, me peguei a Deus, eu sabia que aquele barco não ia sair, que a gente tinha quebrado o mastro antes de chegar em Noronha e graças a Deus que conseguimos monitorar o barco até chegar em Noronha”. Neste pensar, é importante lembrar o estudo de Le Breton ${ }^{2}$, quando apresenta o ordálio e o julgamento de Deus, em que o praticante é levado à metáfora do contato com a morte e recorre a Deus ou aos deuses para garantir sua existência. Outros aspectos considerados pelos entrevistados recaem nos equipamentos de segurança e nos recursos tecnológicos, relatados pelo entrevistado 4:

[...] nós estávamos equipados, com localizador pessoal, ligado a internet, roupas próprias para aguentar tanto o frio, como sol, água, tinha um barco inflável também [...] nós tínhamos certeza que iríamos ser resgatados, e tínhamos rádio que ouvia uma base na terra avisando que o navio se encontrava naquela latitude, que estava precisando de ajuda, e aí o helicóptero passou. Nós sabíamos que ia sermos resgatados por conta desses equipamentos.

Neste mesmo sentido, os estudos de Marinho ${ }^{22}$ apontam para os equipamentos tecnológicos, os quais permitem maior fluidez ao praticante. A tecnologia é um dos fatores de crescimento das práticas corporais na natureza e permite aos praticantes vivenciarem novas sensações, gerenciando o risco, tornando-os calculados. Os riscos nestas práticas são vulneráveis aos praticantes, contudo, é necessário analisar todas as formas de gerenciá-los, para minimizar as causas de acidentes, lesões e doenças propícias, da mesma forma na prática da vela.

\section{Prazer da Prática da Vela}

A sensação de prazer surge, muitas vezes, das situações difíceis arcadas pelos praticantes, após vivenciarem situações selvagens, assumidas com satisfação ${ }^{24}$. A categoria sensação de prazer, apresenta quatro subcategorias: elementos naturais, vencer regatas, emoções/sentimentos, e outros, seguida das variáveis de maior frequência. O diagrama a seguir apresenta as sensações de prazer reveladas a partir da prática da vela.

A subcategoria elementos naturais desperta para a sensação de prazer encontrada no cenário natural, em que são reveladas a partir das vivências das práticas corporais na natureza, experimentando situações híbridas, despertando novas sensações e condições de independência, tais sensações favorecem a relação ser 


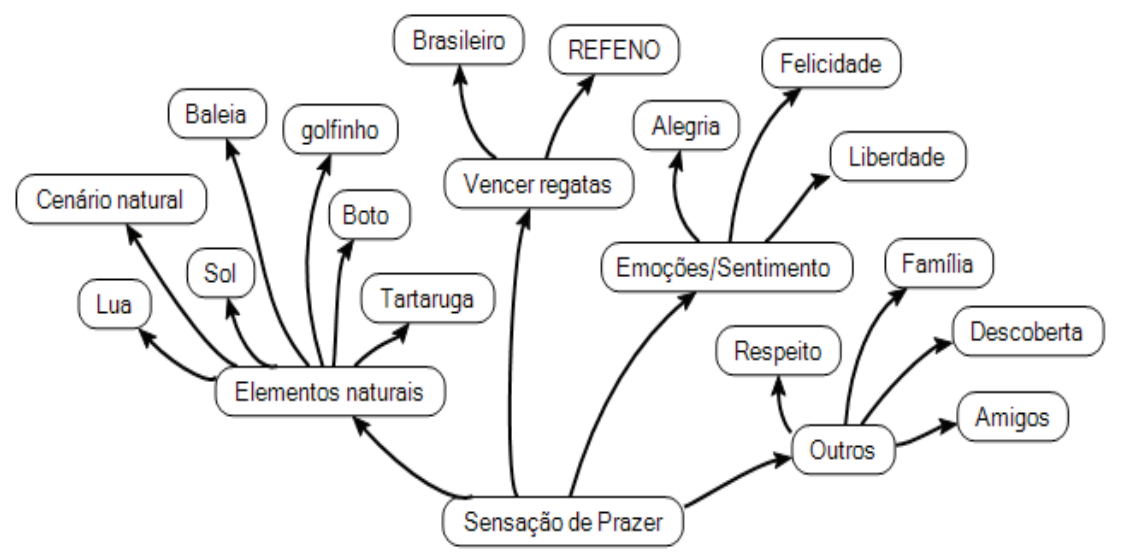

Figura 3 - Elementos que compõem a sensação de prazer na prática da vela.

humano-natureza ${ }^{23}$. O entrevistado 18 revela uma situação singular, em que se sentiu lisonjeado, ao relatar que "[...] tava no final de tarde, era o sol se pondo de um lado e a lua nascendo do outro. Eu me senti como se estivesse no centro". Ainda seguindo este raciocínio, o entrevistado 19 informou que a maior sensação de prazer enquanto velejava foi "[...] quando a gente tava em Ilha Bela e tinha um cardume com mais de 50 golfinhos e a gente velejando ao lado deles". Estas situações permitem aos seres humanos se reconhecerem como elementos integrantes da natureza, ou em estreita simbiose ${ }^{28}$.

Referente à subcategoria vencer regatas, foram relatadas, pelos velejadores, as experiências vividas em duas regatas, o Brasileiro e a Regata Internacional Recife Fernando de Noronha (REFENO), como relata o entrevistado 9, "[...] ganhar um campeonato é uma felicidade muito grande. Você passa por uns anos treinando, querendo atingir seu objetivo, e você ganha esse campeonato... é de chorar, é de se arrepiar dentro do barco, não tem explicação”. Sob os aspectos psicológicos em atletas velejadores, Fernandes et al. ${ }^{29}$ revelaram, em seus estudos, que os fatores psicológicos mais apresentados foram à autoconfiança e a motivação, sendo variáveis de grande importância no que diz respeito ao autocontrole emocional. Sob o mesmo olhar, Moos e Honkomp ${ }^{30}$ apresentam na psicologia educacional os estudos sobre motivação a partir das práticas corporais na natureza, as quais despertam diferentes sensações que contribuem nos aspectos psicoeducaionais.

Quanto à subcategoria emoções/sentimentos, os velejadores apresentaram sensações positivas, destacando-se as sensações de prazer, alegria, felicidade e liberdade, como expõe o entrevistado 3, ao descrever as sensações despertadas ao velejar em Fernando de Noronha, as quais evidenciam "[...] alegria eterna, alegria plena, uma coisa que eu nunca senti na minha vida”. Estudos de Le Breton ${ }^{2,24}$, assim como de Lavoura et al. ${ }^{19}$ e Marinho ${ }^{22,2}$ revelaram que as práticas corporais na natureza permitem despertar sensações prazerosas, quando são alcançados os objetivos, vencendo simbolicamente e, desta forma, ganhando o retorno à vida.

A última subcategoria denominada outros recai nas variáveis que despertaram para as sensações de prazer por meio da prática de vela, em que foram agrupadas as variáveis que indicaram sua importância, porém, não se encaixaram nas subcategorias anteriores, resultando nos elementos família, amigos e respeito, como aponta o entrevistado 13, ao afirmar que as "[...] sensações de velejar com os amigos, com os familiares, de respeitar a natureza, de respeitar os amigos, de respeitar os ambientes, então, todo esse conjunto sempre traz novas sensações”. Os estudos de 
Monteiro ${ }^{20}$ apontaram que as práticas corporais na natureza permitem concretizar formas de amizade e solidariedade, capazes de renovar as relações do praticante consigo mesmo, com o próximo e com a natureza. $\mathrm{O}$ entrevistado 13 complementa seu pensamento afirmando que a prática da vela permite "[...] você descobrir novas praias, novos lugares sempre despertando novas sensações”. Corroboram essa resposta os pensamentos de Bruhns ${ }^{23}$ e Le Breton ${ }^{2}$ quando os autores apontam que as práticas corporais na natureza permitem ao corpo novas descobertas e sensações, contribuindo para o conhecimento do cenário da natureza incerta, resgatando emoções embotadas ou perdidas ao longo do tempo.

As sensações de prazer apresentadas pelos velejadores apontaram para a integração com a natureza por meio de uma "reserva selvagem de sentido", uma vez que o ser humano enfrenta os perigos e ameaças do mar legitimando seu júbilo ${ }^{2}$. Assim, as emoções despertadas trazem sentidos às experiências, as quais ressoam em um estilo de vida, adquirindo valores a partir da prática da vela, os quais são propagados em outras instãncias da vida dos velejadores.

\section{CONSIDERAÇÕES FINAIS}

A prática da vela envolve sentidos e significados que são atribuídos na busca do prazer por meio dos riscos encontrados na natureza incerta. Esta prática foi considerada pelos velejadores entrevistados, como uma atividade física vivenciada no contexto do lazer, capaz de desperta os aspectos emocionais, trazendo novas formas de sensações, como liberdade, poder e tranquilidade.

Os entrevistados perceberam que os riscos ocasionados pela prática da vela são oriundos da quebra de equipamento, falta de manutenção, negligência do velejador e das mudanças climáticas. Nas situações de risco, as sensações se dividem em duas categorias: a primeira, refere-se à ocasião em que as sensações negativas recaem no medo e no desespero; e a segunda, diz respeito à situação posterior, destacando-se sensações positivas, como o alívio e a percepção de nascer novamente. Quanto ao salvamento nas situações de risco, os velejadores revelaram que Deus, os equipamentos de segurança e o apoio dos recursos tecnológicos são fundamentais para uma prática segura.

O discurso do prazer apontou para o entrelaçamento da prática da vela, encontrando-se, no cenário natural, um espaço de conquistas e respeito consigo, com o próximo e a com natureza. Assim, destaca-se o prazer como elemento sedutor desta prática, ainda que este, nem sempre, seja alcançado, devido às incertezas que as práticas corporais na natureza oferecem, sendo estas inseridas em uma dimensão desconhecida, subjetiva e complexa, merecedora de novas investidas em estudos nos mais diversos campos do conhecimento humano.

\section{Agradecimentos / Financiamento}

Coordenação de Aperfeiçoamento de Pessoal de Nível Superior - CAPES, pelo financiamento sob a forma de bolsa de mestrado.

\section{Contribuição dos autores}

P. P. C. Silva conduziu a revisão de literatura, realizou a coleta, transcreveu os dados e efetuou a análise dos dados; E. A. P. P. C. Silva auxiliou na metodologia e análise dos dados; A. M. P. Azevedo e P. V. Moura, contribuíram na coleta de dados e construção dos resultados. G. M. Schwartz, S. Rechia e C.M. S. M. Freitas Auxiliaram na análise dos dados e revisaram criticamente a versão final do estudo. 


\section{REFERÊNCIAS}

1. Silva PPC, Freitas, CMSM. Emoções e riscos nas práticas na natureza: uma revisão sistemática. Motriz 2010; 16(1): 221-230.

2. Le Breton D. Condutas de risco: dos jogos de morte ao jogo de viver. Tradução Lólio Lourenço de Oliveira. Campinas: Autores Associados, 2009.

3. Suassuna D, Barros J, Azevedo A, Sampaio J. A relação corpo-natureza na modernidade. Soc. estado. [online] 2005; 20(1): 23-38.

4. Morin E. O Método 1: a natureza da natureza. Tradução: Ilana Heineberg. 2. ed. Porto Alegre: Sulina, 2005.

5. Bento J. O. Do "Homo Sportivus": relações entre natureza, cultura e técnica. Revista Brasileira de Educação Física e Esporte 2007, 21(4): 315-330.

6. Costa A. S. Desporto e Antropologia. In: Pereira AL, Costa A, Garcia RP. O desporto entre lugares: o lugar das ciências humanas para a compreensão do deporto. Universidade do Porto: Porto, 2006.

7. Vygotsky LS. A formação social da mente. São Paulo: Martins Fontes, 1989.

8. Bakhtin M. Marxismo e filosofia da linguagem: problemas fundamentais do método sociológico na ciência da linguagem, 7. ed. São Paulo: Hucitec, 1995.

9. Abbagnano N. Dicionário de Filosofia. 2. ed. São Paulo: Martins Fontes, 1998.

10. Spink MJ. Trópicos do discurso sobre risco: risco-aventura como metáfora da modernidade tardia. Caderno de Saúde Pública 2001; 17(6): 1277-1311.

11. Spink MJP. Posicionando pessoas como aventureiros potenciais: imagens de risco-aventura em matérias de revista. Psicologia \& Sociedade 2008; 20 (especial): 50-60.

12. Spink MJP, Aragaki SS, Alves MP. Da exacerbação dos sentidos no encontro com a natureza: contrastando esportes radicais e turismo de aventura. Psicologia: Reflexão e Crítica 2005; 18(1): 26-38.

13. Pereira AL. Uma experiência no (pelo) corpo. Revista Portuguesa de Ciências do Desporto 2005; 5(3): 311-321.

14. Carvalho RG, Pereira AL. Percursos alternativos - o Parkour enquanto fenómeno (sub)cultural. Revista Portuguesa de Ciências do Desporto 2008; 8(3): 427-440.

15. Marinho A. Lazer, aventura e ficção: possibilidades para refletir sobre atividades realizadas na natureza. Motriz 2009; 15(1): 1-12.

16. Banks M. Dados visuais para pesquisa qualitativa. J. Fonseca, Trad. Porto Alegre: Artmed, 2009.

17. Minayo MCS. O Desafio do conhecimento: pesquisa qualitativa em saúde. 4. ed. São Paulo: Hucitec - Rio de Janeiro: Abrasco, 1996.

18. Bardin L. Análise de conteúdo. Tradução. Luís Antero Reto e Augusto Pinheiro. Lisboa: Edições 70, 2009.

19. Lavoura TN, Schwartz GM, Machado AA. Aspectos emocionais da prática de atividades de aventura na natureza: a (re)educação dos sentidos. Revista Brasileira de Educação Física e Esporte 2008; 22(2): 129-127.

20. Monteiro SV. Lazer, natureza e amizade: formas de subjetividade na modernidade tardia. In: Marinho A, Bruhns HT. Viagens, lazer e esporte: o espaço da natureza. Barueri: Manole, 2006: 118-149.

21. Schwartz GM, Carnicelli Filho S. (Desin)Formação profissional e atividades de aventura: focalizando os guias de "Rafting”. Revista Brasileira de Educação Física e Esporte 2006; 20(2): 103-109.

22. Marinho A. Lazer, Aventura e Risco: reflexões sobre atividades realizadas na natureza. Movimento 2008; 14(2): 181-206.

23. Bruhns HT. A busca pela natureza: turismo e aventura. Barueri: Manole, 2009.

24. Le Breton D. Aqueles que vão para o mar: o risco e o mar. Natureza. Revista Brasileira de Ciências do Esporte 2007; 28(3): 9-19.

25. Bentley TA; Page S; Edwards J. Monitoring injury in the New Zealand adventure tourism sector: an operator survey. Journal of Travel Medicine 2008; 15(6): 395-403.

26. Pereira AL. Para uma visão fenomenológica do corpo contemporâneo. In: Pereira AL, Costa A, Garcia RP. O Desporto entre lugares: o lugar das ciências humanas para a compreensão do deporto. Universidade do Porto: Porto, 2006. 
27. Spink MJP, Galindo D, Cañs A, Souza DT. Onde está o risco? Os seguros no contexto do turismo de aventura. Psicologia \& Sociedade 2004; 16(2): 81-89, 2004.

28. Moreira JCC, Schwartz GM. Caminho da fé: reflexões sobre lazer e ambiência. Motriz 2010; 16(3): 559-570.

29. Fernandes HM, Bombas C, Lázaro J, Vasconcelos-Raposo J.; Perfil psicológico e sua importância no rendimento em vela. Motricidade 2007; 3(3): 24-32.

30. Moos DC, Honkomp B. Adventure learning: motivating students in Minnesota Moddle School. Journal of Research on Technology in Education 2011; 4(3): 231-352.

Endereço para Correspondência Priscilla Pinto Costa da Silva Rua João Machado, n 90, Bairro: Prata Email: laprisci@gmail.com Recebido 19/02/2013

Revisado 21/02/2013 Tel: (83) 87195118 